\title{
Subjetividade, espiritualidade, gestão e Estado na Educação Popular em Saúde: \\ um debate a partir da obra de Eymard Mourão Vasconcelos
}

Luciano Bezerra Gomes (a)
Emerson Elias Merhy

Gomes LB, Merhy EE. Subjectivity, spirituality, management and State in Popular Health Education: a discussion based on the work of Eymard Mourão Vasconcelos. Interface (Botucatu). Interface (Botucatu). 2014;18 Supl 2:1269-1282.

The article argues that Popular Health Education has a plurality of themes and allows enriching the public health debate in different fields of production. It is based mainly on the analysis of papers written by Eymard Mourão Vasconcelos between 1994 and 2009, systematizing his reflections about the themes of subjectivity and spirituality, management of teams and health services, and the State in the health sector. As this author's proposals are gradually presented, possibilities of discussion with other authors in the health field are suggested. These authors' ideas strengthen or question Vasconcelos' formulations, which shows the richness of the debate that can be generated from such approaches.

Keywords: Popular Health Education. Spirituality and health. Health management. Qualitative research.
O artigo identifica que a Educação Popular em Saúde apresenta uma pluralidade de temáticas, permitindo enriquecer o debate da saúde coletiva em distintos campos de produção. Baseia-se fundamentalmente na análise dos escritos de Eymard Mourão Vasconcelos entre os anos de 1994 e 2009, sistematizando suas reflexões sobre os temas da subjetividade e espiritualidade, gestão de equipes e de serviços de saúde e o Estado no setor saúde. À medida que vão sendo apresentadas as proposições desse autor, apontam-se possibilidades de debate com outros autores do campo da saúde, os quais fortalecem ou questionam as formulações de Eymard, demonstrando a riqueza do debate que pode ser gerado a partir de tais aproximações.

Palavras-chave: Educação Popular em Saúde. Espiritualidade e saúde. Gestão em saúde. Pesquisa qualitativa.

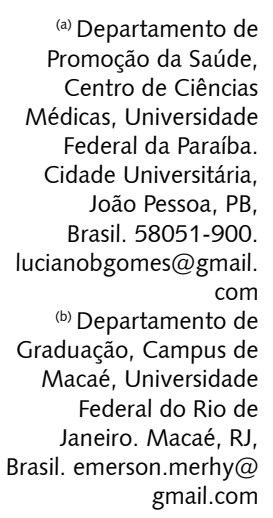

(a) Departamento de Promoção da Saúde, Cénicas, Universidade Federal da Paraíba. Cidade Universitária João Pessoa, PB Brasil.58051-900. com

(b) Departamento de Campus de Federal do Rio de Janeiro. Macaé, RJ, gmail.com 
O campo da saúde, no Brasil, tem apresentado muito pouca capacidade de se abrir para um diálogo profundo interno. Constatamos isso com certa tristeza, pois perdemos em capacidade de nos renovarmos a partir das afetações e da abertura para a produção de transversalidades. Ao perder essas possibilidades de leituras transversais, por exemplo, temos visto diversas pessoas buscarem nos autores do campo da Educação Popular em Saúde apenas suas formulações referentes à educação. Assim fazendo, desperdiçam a possibilidade de interagir com outras perspectivas que esse campo aponta e que pode ajudar a problematizar diversos temas relevantes.

Foi tentando sair de tais monólogos que realizamos uma pesquisa buscando analisar a formulação de autores da Educação Popular em Saúde em relação ao tema do cuidado em saúde, a qual foi desenvolvida como pesquisa no curso de mestrado de um dos autores do presente artigo, tendo o outro autor como seu orientador. A pesquisa se desenvolveu junto à Linha de Pesquisa Micropolítica do Trabalho e o Cuidado em Saúde, do Programa de Pós-Graduação em Clínica Médica da Faculdade de Medicina da Universidade Federal do Rio de Janeiro(c).

Nesta pesquisa, além de realizarmos uma ampla revisão bibliográfica na literatura brasileira, que nos permitiu compreender o surgimento da Educação Popular em Saúde como campo de produção acadêmica e como potente movimento social ${ }^{1}$, também nos debruçamos de modo mais aprofundado sobre a formulação de cuidado presente na obra de Eymard Vasconcelos. A escolha desse autor se deveu à sua prolífera contribuição ao campo, bem como ao seu papel no desenvolvimento de diversas redes que envolvem trabalhadores e pesquisadores dessa área, tendo essa atuação relação direta com tudo que ele produziu.

Debruçamo-nos, assim, sobre toda a obra escrita desse autor, publicada entre os anos de 1994 e 2009, sob os diferentes formatos. Além de sistematizarmos as suas formulações, tentamos apontar possibilidades de debate com outros autores que tomam as disputas em torno da clínica e da produção do cuidado.

Entretanto, ao realizarmos este estudo, identificamos alguns temas que, estando relacionados direta ou indiretamente, ou mesmo margeando o debate sobre a clínica e o cuidado, presentes na obra de Eymard, extrapolam essa seara e colocam algumas questões relevantes para o campo da saúde como um todo. Apresentamos aqui o que sistematizamos da obra desse autor com o recurso às seguintes categorias: Críticas ao racionalismo e concepção de subjetividade e espiritualidade; Gestão do trabalho em equipe; Concepções sobre a gestão da saúde e o Estado.

\section{Críticas ao racionalismo e concepção de subjetividade e espiritualidade}

Vasconcelos afirma que a ciência moderna nega a subjetividade, hipertrofiando a razão instrumental, e identifica, no final do século XX, uma intensificação da valorização das dimensões não racionais presentes na produção do conhecimento e nas ações humanas. Ele afirma, entretanto, que há uma limitação dessas perspectivas, por se reduzirem a abordar as dimensões inconscientes presentes na psicanálise, que não deixa de ser uma leitura racionalista sobre a mente 2 .

Baseando-se em Carl Jung, Eymard defende que o ser humano deve integrar quatro funções psicológicas básicas: a razão, a sensação, a emoção e a intuição. Ele afirma que os trabalhadores da saúde precisam aprender a compreender "também por dimensões que estão além da razão" 3 (p. 182) e que, nos serviços

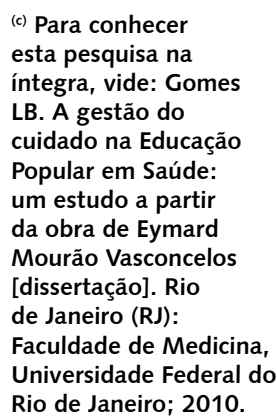


de saúde, grande parte das ações dos profissionais já se baseia em atitudes intuitivas. Além disso, que a dimensão emocional no trabalho em saúde é fundamental para que se avance na construção de caminhos pactuados entre os diversos sujeitos envolvidos ${ }^{2}$.

Diante disso, Vasconcelos pretende associar uma valorização da subjetividade com a perspectiva de emancipação desenvolvida por Karl Marx². Na sua concepção de subjetividade, porém, ele associa-se a autores que fazem esse caminho por meio da valorização da espiritualidade. Um desses autores mais relevantes é Leonardo Boff, uma das referências importantes da teologia da libertação, onde se desenvolveu um diálogo entre o marxismo e os valores cristãos hegemônicos em nossas sociedades latino-americanas, propondo um recorte de classe a uma igreja que faria a opção preferencial pelos pobres.

Esses sujeitos estimularam o desenvolvimento das comunidades eclesiais de base, que representaram um dos espaços marcantes da resistência às ditaduras que se espalharam em nosso continente durante as décadas de 1960 a 19804. Vários coletivos da saúde foram profundamente influenciados, em suas origens, por esses autores e suas práticas, sendo por meio da luta desses coletivos que Vasconcelos se destaca.

Boff afirma que o cuidado se encontra na natureza da essência humana, que é constitutivo do humano, o qual coloca cuidado em tudo o que faz e nele encontra seu ethos fundamental ${ }^{5}$. Esse autor, não obstante reconheça a necessidade de se lutar pelo fortalecimento do cuidado na nossa sociedade, aposta no cuidado como perspectiva teleológica, que se sustenta como valor transcendente na constituição do ser humano. Embora critique perspectivas moralistas, ele concebe o cuidado como valor moral. Mais do que debater a concepção de cuidado de Boff, consideramos que expô-la é uma boa maneira de demonstrar a concepção essencialista de ser humano, presente nesse autor. Para ele:

No fundo, cada pessoa é uma pessoa, única e irrepetível. Ela, pela sua simples presença, significa uma convocação para a Transcendência viva. O ser humano, já o dissemos tantas vezes, representa um projeto infinito e um mistério aberto sobre o inteiro universo. Esse mistério não é o resíduo do ainda não conhecido ou pesquisado. Mas é exatamente aquilo que antecede a todo o conhecimento e se mostra ainda maior após todo o conhecimento. Que é o ser humano? [...] A experiência última do homem não é mais o homem; é a experiência daquilo que transcende o homem; é a experiência do Mistério. Cada homem, por mais pecador e miserável que seja, não pode apagar a Transcendência que se torna transparente em seu semblante. Ele é sempre maior que todos os seus crimes; maior do que todos os seus arroubos de amor e de mística. Nele flui uma torrente de bondade, palpita uma profundidade misteriosa, irrompe um além que constitui a permanente diafania de Deus no mundo. Por isso, o ser humano assoma como o maior sacramento de Deus. Eis de onde provém toda a sacralidade da pessoa humana; daí toda a sua respeitabilidade; daí a identidade afirmada por Cristo entre o amor ao próximo e o amor a Deus. O amor não é mandamento meramente voluntarístico; assim é porque Deus simplesmente o quer. Deus o quer porque ele é o mais importante que existe. E o ser humano é o lugar de sua aparição e realização privilegiada e consciente ${ }^{6}$. (p. 100-1; grifos do autor)

Embora não se refira em seus textos especificamente a essa citação, identificamos que tal perspectiva essencialista do ser humano é assumida também por Vasconcelos, em sua concepção de subjetividade, pois seu reconhecimento das limitações da ciência em produzir a atenção integral às pessoas o leva, "necessariamente", à espiritualidade como saída.

Ao invés de trabalhar com o conceito de religiosidade, prefere a concepção de espiritualidade, entendida por ele de modo semelhante ao que defende Boff: como a vivência da transcendência. Entretanto, segundo Vasconcelos, Boff desenvolveria uma concepção de transcendência na imanência, ou transcendência imanente, por não se referir a uma transcendência como era compreendida historicamente na filosofia, mas por tratar de "uma dimensão, não imediatamente percebida, da realidade concreta, material e cotidiana da existência"2 (p. 31).

Ele entenderia a transcendência como um conceito não necessariamente religioso, mas como "um elã vital, uma vitalidade surpreendentemente dinâmica presente em todo o ser humano que, no entanto, pode estar entorpecida por situações existenciais particulares"2 (p. 32). Boff defende a 
superação do materialismo com a espiritualidade, que religaria o homem ao "Todo" 5 . Embora afirme uma transcendência que não se opõe a uma imanência, acaba transparecendo uma concepção teleológica do homem.

A espiritualidade, segundo Vasconcelos, desenvolve-se no cultivo do contato sistemático com o eu profundo, trazendo a transcendência para o lugar de orientação da consciência no cotidiano da vida. Para tanto, tornar-se-ia necessário permitir momentos de interiorização, de reflexão, meditação, contemplação, de integração consciente com a transcendência. Baseando-se no inconsciente junguiano, ele defende uma concepção de espiritualidade como a vivência de dimensões profundas da subjetividade, do eu. "A conexão com o eu profundo é o canal de abertura para a transcendência. É um caminho importante de ligação do ser humano [...] com a totalidade do $\operatorname{cosmos}^{\prime 2}$ (p. 37), onde o caráter social da espiritualidade se daria pela compaixão.

Consideramos que com essas concepções Vasconcelos desenvolve um arcabouço teórico relevante para lidar com os desafios que ele colocou, entretanto, salientamos que diversas perspectivas dão centralidade à subjetividade sem passar pela concepção de espiritualidade trabalhada por ele. Vários autores rompem com a definição de ser humano, baseada num telos, remetendo-a a sujeitos em constante produção imanente.

Para Nietzsche7, a lógica da moralidade busca instituir um "indivíduo soberano", que se orienta por princípios de "responsabilidade" ditados por sua "consciência", julgando a si e aos outros segundo valores transcendentes, produzindo, assim, homens melhores. Nietzsche se dedica a desconstruir essa perspectiva. Ele entende que "os valores não têm existência em si, não são uma realidade ontológica; são o resultado de uma produção, de uma criação do homem; não são fatos, são interpretações introduzidas pelo homem no mundo"8 (p. 59-60). Segundo o filósofo7, a construção do novo homem passa justamente pela ruptura com todo tipo de transcendência.

Deleuze também refuta a busca de sentidos transcendentes para o ser humano. Segundo ele, "o Abstrato nada explica, devendo ser ele próprio explicado: não há universais, nada de transcendente, de Uno, de sujeitos (nem de objeto), de Razão, há somente processos, que podem ser de unificação, de subjetivação, de racionalização, mas nada mais"9 (p. 182, grifos do autor). Ele busca, então, em Espinosa, uma ética como "tipologia dos modos de existência imanentes", substituindo a moral, "a qual relaciona sempre a existência de valores transcendentes"10 (p. 29). A moral estrutura sistemas de julgamentos, baseados na oposição dos valores entre bem ou mal; já a ética desarticula os sistemas de julgamentos, trabalhando as diferenças qualitativas dos modos de existência em bom ou mau. Na visão de Deleuze, esses sistemas são construídos por sujeitos em relação com o mundo e consigo mesmo.

\section{A subjetividade dos usuários como potência}

Quando estão diante de situações de adoecimento importante, muitos aspectos da vida das pessoas, em especial das suas dimensões subjetivas, são intensamente mobilizados. Segundo Vasconcelos, além de produzir sofrimento, os episódios de adoecimento mais relevantes podem também representar portas de entrada para a transcendência, oportunidades para se ressignificar a existência². Consideramos que tal compreensão permite trabalhar com as potências da doença, saindo da sua mera negação, entendendo-a como experiência também produtora de vida.

Porém, para compreendermos a subjetividade no campo social, precisamos acessar outros conhecimentos, geralmente não desenvolvidos na formação tradicional do profissional de saúde ${ }^{3}$. Um ponto relevante na concepção defendida por Vasconcelos é que a inserção em processos de luta social coletiva leva à produção de novas subjetivações ${ }^{2}{ }^{11}$. Ele se aproxima, aqui, de Guattari e Rolnik ${ }^{12}$, para quem há uma produção social dos processos de subjetivação; uma vez que, segundo esses autores, os processos de subjetivações seriam moldados na luta social.

Para Vasconcelos, "os problemas materiais ganham sentido na vida das pessoas a partir de seus sistemas de valores e crenças que ordenam, interpretam e lhes atribuem prioridades

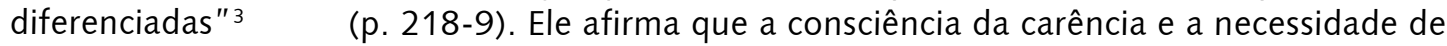
luta para sua superação exigem elaboração mental dos indivíduos. Entretanto, os processos que 
geram tal atitude coletiva variam, pois as condições consideradas adequadas de vida e o que se compreende como direitos de cidadania são singulares ${ }^{3}$.

Ele vai buscar em Victor Valla a concepção de que, em diversas situações, pessoas das classes populares evitam "processos de conscientização", por imaginar que isso exigirá mais ainda da parte delas, que já se encontram vivendo próximo de seus limites ${ }^{3}$. O autor aponta as limitações da concepção de tomada de consciência, dialogando diretamente com Suely Rolnik, que identificou que, nos países mais ricos, há um reconhecimento das pessoas como portadoras de direitos sem que isso represente um acolhimento.

Como o inconsciente seria o que permite acesso às dimensões mais profundas do ser humano, nosso autor propõe uma tomada da inconsciência, para se chegar a uma sociedade mais justa. A tomada da inconsciência representa uma concepção interessante desenvolvida por ele, noção que certamente tem muito a enriquecer num diálogo com as concepções de inconsciente e de desejo como produção presente nas concepções de autores como Deleuze e Guattari, entre outros ${ }^{12,13}$.

\section{Sobre a espiritualidade no trabalho em saúde}

Para Vasconcelos, a educação popular, desde sua origem, esteve muito próxima das questões da religião e da igreja e precisaria, atualmente, compreender e lidar com o atual quadro de diversidade religiosa que vem crescendo no Brasil. Ele reconhece que a vida religiosa se relaciona, em vários aspectos, com a área da saúde. Por um lado, as populações latino-americanas têm uma relação com a religião bastante intensa, construindo por aí muitos dos sentidos de sua existência e produzindo explicações para os processos de adoecimento e cura a que estão submetidas. Por outro lado, muitos profissionais de saúde constituem, na vivência religiosa, os significados para sua vida e das dimensões éticas no seu trabalho. Por fim, há uma longa e relevante história da prestação de serviços de saúde pelas entidades religiosas².

Segundo o autor, quando a vivência da transcendência se desenvolve como divina, de um modo a "revelar a presença de um Outro na alma humana" 2 (p. 45, maiúscula como grifo do autor), a espiritualidade pode ser chamada de religiosidade. Entretanto, seria possível a interlocução entre pessoas que têm uma vivência religiosa da espiritualidade com outros que desenvolvem uma vivência não religiosa, pois a experiência subjetiva seria semelhante entre elas.

Ele propõe debatermos explicitamente essa temática, pois "as práticas religiosas têm estado presentes no trabalho de saúde de forma pouco crítica e elaborada, uma vez que nele se infiltram de modo silencioso e não debatido"2 (p. 24). Além do estudo de diversas disciplinas, que abordam o tema da espiritualidade, Vasconcelos acredita que os profissionais deveriam se lançar intensamente aos caminhos da própria espiritualidade. Seria preciso se buscar o autoconhecimento profundo.

Ele defende que desenvolver a própria espiritualidade é uma maneira relevante de o profissional trabalhar melhor com as afetações presentes em elementos transferenciais inerentes ao processo terapêutico constitutivo do trabalho em saúde. Na prática clínica, a transferência é um elemento fundamental, por permitir: considerarmos o protagonismo e singularidade dos sujeitos; compreendermos os fluxos de afetos presentes naquela etapa da vida dos sujeitos, ajudando a construir uma visão mais ampliada do outro, permitindo a construção de propostas mais potentes de superação das dificuldades.

Tal conceito é bastante desenvolvido pelas várias psicanálises e por algumas correntes da análise institucional ${ }^{14}$. Lidar com as várias dimensões subjetivas, que são mobilizadas no encontro com os usuários, é um aspecto que, segundo Vasconcelos, poderia ser facilitado no profissional que tem mais abertura para a própria espiritualidade².

O autor propõe a espiritualidade também como caminho para a promoção da saúde. Afirma que não conseguimos apoiar a melhoria da saúde da população apenas com argumentos racionais e medidas institucionais. Defende a necessidade de se perceber, comunicar-se e ajudar no aprofundamento de crenças, utopias e valores presentes na concepção de vida dos coletivos. Para ele, a transformação causada pela vivência da doença pode gerar mobilizações de energias coletivas, 
promovendo o desenvolvimento ou ampliação de lutas que anteriormente tinham grande dificuldade em serem desencadeadas. A luta coletiva em parceria com as classes populares levaria ao amor como construção ética para as relações².

\section{Gestão do trabalho em equipe}

Um dos valores mais relevantes para a educação popular é a construção coletiva das lutas. Nessa perspectiva, devem-se evitar iniciativas isoladas, pois as atividades construídas coletivamente têm maior potencial de transformação e de continuidade ${ }^{3}$. Assim, Vasconcelos se questiona sobre o modo como se dão as relações entre os trabalhadores de saúde, bem como pensa em maneiras de se conduzir melhor a gestão do trabalho entre eles.

Ele defende que as equipes que se orientam pelos princípios da Educação Popular em Saúde desenvolvem outras interações, ao se questionarem sobre as relações de poder estabelecidas. Considera que mesmo profissionais sem formação específica, mas que atuam em serviços de saúde, precisam passar a participar das discussões sobre o funcionamento do serviço, assim como serem qualificados para realizarem seus trabalhos de modo a se tornarem, com suas especificidades, também cuidadores ${ }^{15}$.

Ele identifica potências na complexificação das redes de cuidado, em que os profissionais precisam se articular para produzir a integralidade da atenção. Ao mesmo tempo, concorda que o campo da saúde é atravessado de disputas pelo controle de determinados setores de atenção à saúde, como quando eventualmente profissionais da saúde mental tentam manter certo monopólio da ação sobre aspectos afetivos no trabalho coletivo ${ }^{3}$.

Para potencializar o modo como os profissionais precisam se articular no seu trabalho, Gastão Campos propõe que eles pactuem constantemente as ações que são específicas de cada profissional, que constituiriam o seu núcleo de competências, compartilhando as ações que deveriam ser comuns a todos, que estariam dentro do campo de competências de todos os profissionais da saúde. A negociação das atribuições nucleares e do campo de atribuições comuns é fundamental, pois elas não são estanques, variando de acordo com a constituição de cada equipe, com os problemas com os quais estão lidando e, mesmo, com a singularidade de cada usuário ${ }^{16-18}$.

Dialogando com tal perspectiva, Ricardo Ceccim propõe que esse trabalho em equipe multiprofissional, entretanto, seja orientado segundo uma perspectiva entredisciplinar, onde os saberes não se agregariam apenas, mas se relacionariam, inclusive, delimitando as situações para as quais eles reconheceriam suas insuficiências e se lançariam ao desafio de produzir o novo ${ }^{19}$.

Utilizando outros conceitos, Vasconcelos defende a educação em saúde como campo de práticas de todos os profissionais e não como saber nuclear a determinada categoria profissional ou a especialistas em educação. Na sua perspectiva, poderíamos afirmar a Educação Popular em Saúde como elemento do campo comum de atuação do conjunto dos profissionais, permitindo o desenvolvimento de relações entredisciplinares ${ }^{11}$.

Vasconcelos, ao discutir a necessidade de dialogicidade na sua reflexão sobre a Educação Popular em Saúde, coloca questões que podem ser trabalhadas de modo muito próximo a reflexões sobre o cuidado, gerando ofertas importantes para se pensar a gestão do cuidado em equipes de saúde. Por exemplo, afirma que, ao propor processos coletivos de construção de intervenções:

diante de uma situação complexa, o importante é fazer uma roda de conversa, problematizar a situação de modo participativo e buscar estudos teóricos que contribuam no seu entendimento. Mas trata-se de uma problematização não presa apenas ao debate de aspectos biológicos e sanitários. Mesmo o problema mais corriqueiro de saúde está ligado com questões sociais globais. É o entendimento de cada questão, relacionando suas dimensões biológicas, psicológicas, ambientais, culturais, sociais, econômicas e políticas, que permite uma compreensão mais profunda ${ }^{11}$. (p. 291)

De certo modo, configura-se aqui uma proposta de construção coletiva do que alguns autores denominam por projetos terapêuticos singulares (PTS), em que são articuladas intervenções de diversos 
atores para se alcançarem metas pactuadas coletivamente, que vão desde tratamento medicamentoso individual à articulação de reuniões com representantes do poder público ${ }^{3,14}$.

A elaboração de PTS busca instituir novos sentidos para as reuniões de equipe, trazendo para o foco não aspectos normativos, mas as necessidades de se ofertarem modos mais qualificados de se produzir a atenção. Campos $^{20}$ analisa que nem todas as situações que chegam à unidade de saúde demandam a elaboração coletiva de um PTS por parte da equipe, propondo que se discutam e definam coletivamente as situações que exigem tal abordagem.

A construção de projetos terapêuticos singulares deve envolver todos os trabalhadores, permitindo que várias pessoas possam contribuir de modos diferentes, de acordo com os distintos vínculos existentes e saberes que manejam, na análise do caso em sua singularidade, na proposição de caminhos e na sua coordenação $0^{14,21}$.

Para atuar em relações de trabalho tão complexas, lidando com situações de vida de intenso sofrimento, Vasconcelos propõe que os profissionais desenvolvam estratégias de processamento dos próprios afetos. Diante de determinadas situações do trabalho em saúde, reage-se com dúvida, imobilidade, depressão, raiva, indignação, perplexidade, entre outras possibilidades.

Diante disso, ele afirma a necessidade de os profissionais desenvolverem processos de autoanálise, a fim de lidarem com tais dimensões interiores que os afetam, podendo ser mesmo por meio de escrita reflexiva das suas vivências. Ao mesmo tempo, o autor faz severa crítica aos processos de educação dos profissionais de saúde, que se organizam em treinamentos com a intenção de repassar informações ${ }^{3,11}$.

Tanto para permitir outras maneiras de desenvolver o processo de aprendizagem, mas também para ajudar os trabalhadores a lidarem com as dimensões afetivas que estão relacionadas ao seu cotidiano profissional, como ainda para disparar a instituição de novas relações micropolíticas nos serviços, vários autores propõem a estratégia da educação permanente em saúde, em que as diversas dimensões do trabalho em saúde são tomadas como objeto para o processo coletivo de reflexão22.

Embora conheça tais reflexões sobre a educação permanente, Vasconcelos defende a educação popular como método para lidar com as relações na equipe. De certa forma, para ele, o que não é educação popular, acaba sendo trabalhado como "práticas educativas formais". Não há em seus textos grandes aberturas para discussão, interlocução, explicitação de possibilidades de diálogo com outras perspectivas pedagógicas, que eventualmente tivessem capacidade de serem agregadas ou, em algumas situações, de substituir a educação popular.

Ele até realiza, em alguns momentos, críticas relevantes à educação popular, por exemplo, ao afirmar que "símbolos e gestos têm significado educativo que repercute independentemente de sua verbalização. Mas a educação popular tem, tradicionalmente, se restringido à consideração de dimensões conscientes de trocas de $\operatorname{saber"3~}^{3}$ (p. 51). Mesmo assim, ele sempre se remete à educação popular como o método adequado para lidar com a necessidade de diálogo entre trabalhadores e usuários, bem como para mediar as interações entre os trabalhadores nas relações de equipe e com os gestores.

O autor afirma que a educação popular não é a única perspectiva pedagógica que se baseia na problematização, entretanto, considera "a pedagogia não diretiva baseada na problematização que mais consegue integrar as dimensões política, cultural, ecológica, subjetiva e técnica"11 (p. 279).

Considera, ainda, que o adjetivo popular presente na denominação da perspectiva da educação popular não se remete ao público à qual ela é destinada, sendo possível trabalhá-la com estudantes universitários e trabalhadores da saúde, por exemplo, que também vivem relações de opressão e de degradação institucional. Essa concepção é, em parte, o que o leva a defender a educação popular como o método adequado a ser utilizado nos processos de formação de profissionais de saúde nos cursos de graduação e pós-graduação, bem como nos processos de educação permanente dos trabalhadores que atuam nos serviços de saúde ${ }^{11}$.

Ainda, sobre as relações que se desenvolvem nos estabelecimentos de saúde, Vasconcelos faz uma reflexão sobre a constitutividade do conflito, o qual estaria sempre presente nos processos em que há investimento de pessoas que se envolvem com o cotidiano dos serviços. Para ele, haveria muitos caminhos e distintas formas de enxergar e lidar com os conflitos, não sendo possível sua superação apenas com boas doses de bom senso, compreensão e de amor entre os diferentes membros. 
Essa concepção é relevante, até porque rompe com uma concepção funcionalista, muito forte ainda, baseada na teoria geral dos sistemas, na qual se considera que existe um único propósito para o conjunto das pessoas e processos de trabalho, no caso a promoção da saúde da população, o qual seria suficiente para ordenar as atividades técnicas e administrativas dos serviços. Existiria um objetivo geral comum a todos os atores envolvidos no sistema. Entretanto, tais concepções não se sustentam quando observamos, por exemplo, os fortes interesses corporativos operando no cotidiano dos serviços de saúde, segundo seus múltiplos projetos privados ${ }^{23}$.

Diante disso, temos a necessidade de elaborarmos arranjos organizacionais em que as diferentes disputas existentes entre os projetos que atravessam os serviços de saúde sejam explicitadas e publicizadas. Mas, para além da mediação dos conflitos, necessitamos também de um modelo de gestão em que o conjunto dos sujeitos envolvidos possa participar dos processos de análise da situação, definição de prioridades e avaliação das propostas implementadas. Ante tal desafio, Vasconcelos propõe a criação de espaços periódicos de reunião, em que os sujeitos poderiam analisar conjuntamente e definir as melhores soluções, negociando com as diferenças existentes nos grupos ${ }^{15}$.

Segundo Gastão Campos, uma estratégia importante seria pensar em arranjos organizacionais na produção dos serviços de saúde que permitam outras relações entre os sujeitos, como romper com determinados desenhos tradicionais e propor organizações de unidades produtivas de acordo com os valores de uso agregados para o cuidado e os coletivos necessários para sua produção.

A gestão dessas unidades produtivas deveria contemplar, necessariamente, os sujeitos que trabalham nelas, independentemente de categorias profissionais ou outros recortes administrativos. A implementação de espaços de cogestão dos serviços de saúde se inscreve nas propostas que tentam superar o modelo hegemônico, de base taylorista, de gestão de serviços de saúde, apostando que os sujeitos se coproduzem ao mesmo tempo que produzem os atos de saúde. Esses espaços teriam funções básicas administrativas, políticas, pedagógicas e terapêuticas. A constituição dessas estratégias dependeria da vontade política dos diferentes atores envolvidos, bem como da existência de condições objetivas para tanto.

Campos parte do pressuposto de que os espaços de cogestão fortalecem a constituição de sujeitos e a democracia institucional, diminuindo a alienação dos trabalhadores no processo de cuidado, gerando outros tipos de corresponsabilização, ampliando suas capacidades de análise e de intervenção sobre a realidade, facilitando a circulação de saberes e potencializando a expressão de afetos e a maneira como se lidam com as relações intersubjetivas no coletivo organizado ${ }^{16,17}$.

Diferentes interesses existem entre os atores que constroem os serviços de saúde e, neles e em suas práticas, apresentam-se aspectos de suas singularidades, mas também aí refletem as forças hegemônicas e em disputa na sociedade. Essa situação seria geradora de conflitos no serviço, os quais se apresentariam explicitamente, ou ficariam encobertos. Tais conflitos, entretanto, deveriam ser encarados e trabalhados como matéria-prima importante para a gestão e a construção de novos pactos, que temporariamente responderiam melhor aos diferentes interesses em jogo 16,17,24.

Vasconcelos acredita que a educação popular permite uma construção mais elaborada e adequada de ações para se lidar com os conflitos. Seu potencial de promover uma melhor condução de situações conflituosas se daria pelo fato de permitir "ampliação dos canais de interação cultural, negociação de interesses, troca de saberes, intercâmbio de sentimentos e explicitação de significados simbólicos presentes na relação entre os diferentes atores envolvidos nos problemas de saúde"3 (p. 265).

Para além do debate da constituição de espaços coletivos dentro do serviço, Vasconcelos também acredita que "as mudanças institucionais não passam necessariamente por decisões acordadas explicitamente nas reuniões" ${ }^{3}$ (p. 97). Ele enfatiza a dinâmica potente dos espaços informais como lugar de se processarem as emoções dos profissionais. Para ele, as conversas informais e as iniciativas não discutidas teriam poder educativo e político importante e não deveriam ser desvalorizadas. Ponderamos, entretanto, que é preciso construir parâmetros éticos para que os espaços informais não se constituam em lugares onde a vida dos outros seja definida, sem que eles possam participar desses processos ${ }^{25}$. 


\section{Concepções sobre a gestão da saúde e o Estado}

Um aspecto fundamental - embora numa leitura menos atenta até possa parecer secundário -, na obra de Vasconcelos, refere-se à concepção que ele tem da gestão da saúde, sobre as possibilidades de transformar a produção da saúde a partir do lugar da gestão, entre outras questões que versam sobre a ocupação de instâncias governamentais na estrutura do Estado.

Para dar a dimensão disso, vale resgatar a primeira dedicatória presente em um de seus livros, em que ele o oferece:

aos modernos barões e duquesas do setor saúde que, inspirados no desejo de expandir os serviços à população, mas seduzidos pelo poder, se têm empenhado com extremo ardor e radical intolerância na reforma do sistema de saúde por meio da racionalidade administrativa gestada na indústria capitalista. Instigado por seus autoritarismos e por suas desconsiderações sobre a complexidade da dinâmica de relação entre os serviços de saúde e a população, mobilizei-me nessa pesquisa para respeitosamente pronunciar, com maior clareza, minha discordância 3 . (p. 7, grifos do autor)

Em diversos momentos do referido livro, ele vai desenvolvendo uma visão crítica da gestão, que tende a aparecer como absorvida em projetos próprios, descolados dos interesses e ritmos dos movimentos locais ${ }^{3}$. Vale salientar que a tese, que deu origem a esse livro, foi desenvolvida a partir de uma pesquisa-ação realizada por ele em uma unidade de saúde no município de Belo Horizonte, no primeiro mandato da gestão reconhecida como iniciadora da construção de uma das mais robustas redes de saúde do país ${ }^{26}$. Sendo assim, podemos inferir que não é por desconhecer experiências importantes de gestão pública da saúde que Vasconcelos desenvolve uma concepção crítica como a que apresenta.

Acreditamos que a base de suas concepções pode ser encontrada na crítica que faz à "administração científica" taylorista, associada ao fordismo, que levou à fragmentação do processo de trabalho nos serviços de saúde, entre outros aspectos. Nessa perspectiva, a divisão do trabalho não se limita à produção material, expandindo-se para a produção intelectual e também do setor saúde. Ele compreende que tal lógica, que alienaria o trabalhador do produto de seu trabalho, embora tenha servido para o desenvolvimento do capital, também foi assimilada pelas experiências soviéticas de gestão do Estado. Ele faz uma análise do papel que o Estado cumpriu no desenvolvimento do capital, enfatizando o modelo keynesiano no século XX, e como tal Estado passou, progressivamente, a ser regido pelas lógicas da "administração científica do trabalho".

A partir disso, identifica nesses movimentos uma despersonalização da dominação burguesa, afirmando que a expansão dessa lógica, entre outros campos, tem sido hegemônica na maneira como vêm sendo implementados os serviços de atenção primária para as classes populares, em que haveria uma intensa alienação dos trabalhadores, uma restrição das ações a técnicas simplificadas e uma ampliação do poder de burocratas que assumem a gestão do sistema ${ }^{27}$.

É no bojo dessa análise dos interesses do capital que Vasconcelos desenvolve sua concepção sobre a gestão da saúde, apontando uma crítica a boa parte da esquerda sanitária brasileira. Para ele, a atuação, a partir do lugar do Estado, estaria, em último caso na quase totalidade das vezes, desenvolvendo ações em prol dos interesses das elites.

Compreendendo, dessa forma, a atuação por dentro da estrutura do Estado, ele defende que é preciso ir além da luta pela apropriação e expansão estatal dos serviços médicos e da tentativa de desenvolver uma racionalização gerencial dos recursos, pois isso só teria ampliado os espectros de exploração capitalista sobre a vida. Assim, ele convoca-nos a questionar a própria racionalidade que vem sendo implementada nesses serviços ${ }^{27}$.

Contra tal concepção taylorista de gestão, ele propõe a "organização do trabalho baseada na autogestão, a administração realizada a partir da participação de todos os profissionais"15 (p. 63-4). Além disso, Defende que os serviços de saúde sejam controlados pelos trabalhadores organizados, considerando que "a democracia mais profunda se assenta sobre a democracia no mundo da produção. 
O próprio trabalho em saúde é uma frente de luta pela criação de uma sociedade onde cada setor produtivo será gerido de forma democrática"15 (p. 64).

Outros autores concordam com as propostas de democratização da gestão defendidas por ele, embora apresentem outras maneiras de compreender o papel do Estado nesse processo, bem como as possibilidades de luta a partir da ocupação dos espaços de gestão governamental. Acreditam que é possível tornar realmente público o processo de gestão, desenvolver novos coletivos, que disputem lógicas distintas nas relações políticas e institucionais no Estado, garantindo outra atenção à vida de milhões de pessoas a partir da rede pública.

Gastão Campos e Emerson Merhy, por exemplo, concordam que a gestão dos serviços deveria (e poderia) se dar de forma compartilhada e coletiva, considerando os trabalhadores como sujeitos e não como meros recursos, de modo que os diversos interesses privados pudessem ser publicizados e trabalhados por todos, explicitando as disputas e construindo pactos provisórios para o funcionamento dos serviços. Desenvolver tal gestão nos serviços de saúde, entretanto, exige apostas na construção de espaços onde a micropolítica do cuidado possa ser trabalhada coletivamente, inclusive nos espaços de gestão governamental|16,17,28.

A análise de Vasconcelos aposta pouco nas possibilidades de se disputarem outras lógicas de governo por dentro do Estado. Ele concebe o Estado como sendo a cristalização dos interesses da classe dominante; no caso da sociedade capitalista, dos interesses da burguesia. Como destaca Sader ${ }^{29}$, a origem desse Estado deveria ser compreendida na própria evolução da classe burguesa:

À sua forma de existência como classe hegemônica, a burguesia faz corresponder formas políticas determinadas, conforme o estágio de desenvolvimento em que se encontre. Neste momento em que essa hegemonia se define, a necessidade de revolucionar incessantemente as forças produtivas faz com que, politicamente, seja possível um Estado que se identifique com a Nação29. (p. 69, grifos do autor)

Numa perspectiva distinta, para Foucault ${ }^{30}$, precisamos rever e combater, em nossas análises, a hipervalorização do Estado, pois, em nosso momento histórico, mais importante do que a estatização da sociedade é o que ele denominou por "governamentalização" do Estado. Ele afirma que não se governam os Estados, e sim o que se governa é a própria vida, os homens é que se governa. Esse autor situa o nascimento do Estado por dentro do desenvolvimento de uma certa "governamentalidade", conceito este que define como:

o conjunto constituído pelas instituições, os procedimentos, análises e reflexões, os cálculos e as táticas que permitem exercer essa forma bem específica, embora muito complexa, de poder que tem por alvo principal a população, por principal forma de saber a economia política e por instrumento técnico essencial os dispositivos de segurança. Em segundo lugar, por "governamentalidade" entendo a tendência, a linha de força que, em todo o Ocidente, não parou de conduzir, e desde há muito, para a preeminência desse tipo de poder que podemos chamar de "governo" sobre todos os outros - soberania, disciplina - e que trouxe, por um lado, o desenvolvimento de toda uma série de saberes. Enfim, por "governamentalidade", creio que se deveria entender o processo, ou antes, o resultado do processo pelo qual o Estado de justiça da Idade Média, que nos séculos XV e XVI se tornou o Estado administrativo, viu-se pouco a pouco "governamentalizado". ${ }^{30}$ (p. 143-4, grifos do autor)

Para Foucault, o Estado se constituiu a partir do desenvolvimento das técnicas de poder, como uma produção de uma sociedade "governamentalizada". Desse modo, não é uma coisa: "não se pode falar do Estado-coisa como se fosse um ser que se desenvolve a partir de si mesmo e que se impõe por uma mecânica espontânea, como que automática, aos indivíduos. O Estado é uma prática" 30 (p. 369).

De certa forma, embora reconheça o papel que a "administração científica do trabalho" desempenhou no desenvolvimento do Estado burguês, parece ser, em último caso, a "mecânica" ou a "física" da evolução de um Estado-coisa, segundo os interesses da classe burguesa, que orienta a leitura realizada por Vasconcelos. 
Novamente recorrendo a Foucault: "O Estado não pode ser dissociado do conjunto das práticas que fizeram efetivamente que ele se tornasse uma maneira de governar, uma maneira de agir, uma maneira também de se relacionar com o governo" 30 (p. 369).

Não foi com a criação do ente Estado que se desenvolveram uma série de aparelhos para manutenção e reprodução de seu poder; pelo contrário, o Estado representa um novo arranjo de um conjunto de instituições preexistentes. Ele se configura como um efeito de uma razão governamental, que produziu uma racionalização da arte de governar ${ }^{30}$. Considerando essas reflexões de Foucault, entre outras possíveis referências, acreditamos ser relevantes as possibilidades de atuação no espaço governamental, não como única instância, mas como lugar possível de se agir no sentido de se desenvolverem outras lógicas de governo dos homens, com os homens, disputando, assim, com a "governamentalidade" vigente.

\section{Considerações finais}

Enfim, sem pensar que esgotamos todos os debates que podem ser desencadeados a partir das instigantes questões colocadas por Eymard Vasconcelos em seus textos, consideramos que chegamos ao objetivo que tínhamos: demonstrar as possibilidades de enriquecimento de todas as perspectivas da saúde coletiva ao rompermos alguns "nichos" de reprodução e transitarmos em diálogos respeitosos e solidários entre as distintas matrizes existentes.

Perceber a Educação Popular em Saúde como um campo de formulação restrito ao tema da Educação em Saúde é incorrer num equívoco tão grande quanto seria considerar que a formulação de educação permanente em saúde se limitaria a debater de forma também restrita à formação continuada dos profissionais. Superemos tais posturas e apostemos na abertura para nos engravidarmos mutuamente, para nos desenvolvermos na produção radical da diferença.

\section{Colaboradores}

Luciano Bezerra Gomes participou da concepção do projeto, realizou a pesquisa bibliográfica e sua análise, e elaborou a redação final do artigo. Emerson Elias Merhy participou da concepção do projeto, orientou a pesquisa bibliográfica e sua análise, revisou e orientou a redação final do artigo.

\section{Referências}

1. Gomes LB, Merhy EE. Compreendendo a Educação Popular em Saúde: um estudo na literatura brasileira. Cad Saude Publica. 2011; 27(1):7-18.

2. Vasconcelos $E M$, organizador. A espiritualidade no cuidado e na educação em saúde. In: A espiritualidade no trabalho em saúde. São Paulo: Hucitec; 2006. p. 13-157.

3. Vasconcelos EM. Educação Popular e a Atenção à Saúde da Família. 4a ed. São Paulo: Hucitec; 2008.

4. Sader E. A nova toupeira: os caminhos da esquerda latino-americana. São Paulo: Boitempo; 2009.

5. Boff L. Saber cuidar: ética do humano - compaixão pela terra. Petrópolis: Vozes; 1999.

6. Boff L. Experimentar Deus: a transparência de todas as coisas. Campinas: Verus; 2002.

7. Nietzsche F. Genealogia da moral: uma polêmica. Tradução, notas e posfácio Paulo César de Souza. São Paulo: Companhia das Letras; 1998.

8. Machado R. Nietzsche e a verdade. 2a ed. Rio de Janeiro: Graal; 2002. 
9. Deleuze G. Conversações, 1972-1990. Tradução Peter Pál Pelbart. São Paulo: Ed. 34; 1992.

10. Deleuze G. Espinosa: filosofia prática. São Paulo: Escuta; 2002.

11. Vasconcelos EM. Formar profissionais de saúde capazes de cuidar do florescer da vida. In: Vasconcelos EM, Frota LH, Simon E, organizadores. Perplexidade na universidade: vivências nos cursos de saúde. São Paulo: Hucitec; 2006. p. 265-308.

12. Guattari F, Rolnik S. Micropolítica: cartografias do desejo. 7a ed. São Paulo: Vozes; 2005.

13. Deleuze G, Guattari F. Mil platôs: capitalismos e esquizofrenia. Rio de Janeiro: Ed. 34; 1997. v. 2.

14. Cunha GT. A construção da clínica ampliada na atenção básica. São Paulo: Hucitec; 2005.

15. Vasconcelos EM. Educação Popular nos Serviços de Saúde. 3a ed. São Paulo: Hucitec; 1997.

16. Campos GWS. Subjetividade e administração de pessoal: considerações sobre modos de gerenciar o trabalho em equipes de saúde. In: Merhy EE, Onocko R, organizadores. Agir em saúde: um desafio para o público. 2a ed. São Paulo: Hucitec; 2002. p. 229-66.

17. Campos GWS. Um método para análise e co-gestão de coletivos: a constituição do sujeito, a produção de valor de uso e a democracia em instituições: o método da roda. São Paulo: Hucitec; 2000.

18. Campos GWS. Equipes de referência e apoio especializado matricial: um ensaio sobre a reorganização do trabalho em saúde. Cienc Saude Colet. 1999; 4 (2):393-403.

19. Ceccim RB. Equipe de saúde numa perspectiva entre-disciplinar na produção dos atos terapêuticos. In: Pinheiro R, Mattos RA, organizadores. Cuidado: as fronteiras da integralidade. 3a ed. Rio de Janeiro: Cepesc/UERJ, IMS, Abrasco; 2006. p. 259-78.

20. Campos GWS. Saúde Paidéia. São Paulo: Hucitec; 2003.

21. Carvalho $S R$, Cunha GT. A gestão da atenção à saúde: elementos para se pensar a mudança da organização na saúde. In: Campos GWS, Minayo MCS, Akerman M, Junior MD, Carvalho YM, organizadores. Tratado de Saúde Coletiva. São Paulo: Hucitec; 2006. p. 737-68.

22. Ceccim RB, Feuerwerker LCM. O quadrilátero da formação para a área da Saúde: ensino, gestão, atenção e controle social. Physis. 2004; 14(1):4-65.

23. Campos GWS, Merhy EE, Nunes ED. Planejamento sem normas. 2a ed. São Paulo: Hucitec; 1994.

24. Cecilio LCO. É possível trabalhar o conflito como matéria-prima da gestão em saúde? Cad. Saude Publica. 2005; 21(2):508-16.

25. Merhy EE. Ações políticas para... In: Oficina realizada no $8^{\circ}$ Congresso da Rede Unida; 2009; Salvador, Brasil. Salvador; 2009. Anotações.

26. Campos CR, Malta DC, Reis AT, Santos AF, Merhy EE, organizadores. Sistema Único de Saúde em Belo Horizonte: reescrevendo o público. São Paulo: Xamã; 1998.

27. Vasconcelos EM. O taylorismo e a construção da medicina das classes populares. Serv Soc Soc. 1989; 31:56-74.

28. Merhy EE. Um dos grandes desafios para os gestores do SUS: apostar em novos modos de fabricar os modelos de atenção. In: Merhy EE, Magalhães Júnior HM, Rimoli J, Franco TB, Bueno WS, organizadores. O trabalho em saúde: olhando e experienciando o SUS no cotidiano. São Paulo: Hucitec; 2003. p. 15-35.

29. Sader E. Estado e política em Marx: para uma crítica da filosofia política. 2a ed. São Paulo: Cortez; 1998.

30. Foucault M. Segurança, território, população: curso dado no Collège de France (19771978). São Paulo: Martins Fontes; 2008. 
Gomes LB, Merhy EE. Subjetividad, espiritualidad, gestión y Estado en la Educación Popular en Salud: un debate a partir de la obra de Eymard Mourão Vasconcelos. Interface (Botucatu). 2014;18 Supl 2:1269-1282.

El artículo identifica que la Educación Popular en Salud presenta una pluralidad de temas que permiten enriquecer el debate de la salud colectiva en diferentes campos de producción. Se basa fundamentalmente en el análisis de las obras escritas por Eymard Mourão Vasconcelos entre los años 1994 y 2009, sistematizando sus reflexiones sobre los temas de la subjetividad y espiritualidad, gestión de equipos y de servicios de salud y el Estado en el sector de la salud. A medida que se presentan las propuestas de ese autor, se muestran posibilidades de debate con otros autores del campo de la salud quienes fortalecen o cuestionan las formulaciones de Eymard, demostrando la riqueza del debate que puede generarse a partir de tales aproximaciones.

Palabras clave: Educación Popular en Salud. Espiritualidad y Salud. Gestión en salud. Encuesta cualitativa. 
